\title{
The study of infantile hydrocephalus with combined air and isotope ventriculography
}

\author{
DOV FRONT ${ }^{1}$, WILLEM J. OVERBEEK, AND LOURENS PENNING ${ }^{2}$
}

\author{
From the Department of Neuroradiology, University Hospital, Groningen, The Netherlands
}

SUMMARY A method for a combined air and isotope ventriculography is described. Twenty-nine infants with suspected hydrocephalus were studied. The merit of the combined study is the possibility of obtaining both anatomical and functional information. A very small amount of radioactivity-15 $\mu \mathrm{c}$-was found to give satisfactory results. Patterns of cerebrospinal fluid flow in communicating and non-communicating hydrocephalus and in cases of porencephalic cyst and complete obstruction of the lateral ventricles are described.

The intrathecal introduction of radioisotopes for the study of cerebrospinal fluid dynamics ( $\mathrm{Di}$ Chiro, Reames, and Matthews, 1964; Di Chiro, 1964, 1966; Bannister, Gilford, and Kocen, 1967) has provided a better understanding of the pathophysiology of hydrocephalus and a more solid base of indication for shunting procedures. Scintigraphic examination of the subarachnoid space after intrathecal injection of radioisotopes has become a decisive investigation in the study of communicating hydrocephalus in adults. It has also been applied in children (McCullough and Luessenhop, 1969). However, because hydrocephalus in children is, in many cases, of the non-communicating type, intrathecal injection is impractical and intraventricular injection is the method of choice.

The first investigations of infantile hydrocephalus by intraventricular injection of radioisotope were made by an indirect method (Bell, 1957; Atkinson and Foltz, 1962). The amount of radioactivity was measured at different sites to assess the nature of the disturbance of flow of cerebrospinal fluid.

A more direct approach is scanning, enabling both 'visualization' of the ventricles and subarachnoid space, and study of cerebrospinal fluid dynamics. Spoerri and Rösler (1965) were the first to use the method for clinical study of hydrocephalus in children. One of us (Overbeek, 1968) reported the preliminary results of combined intraventricular injection of isotope and air. In the same year Brocklehurst described

\footnotetext{
1 Present address: Department of Neurology, Tel Hashomer Government Hospital, Israel.

2 Reprint requests to Dr. Penning.
}

the results of a study in 29 patients with hydrocephalus of various causes studied by isotope ventriculography. Castellino, Zatz, and DeNardo (1969) reported the study of five cases of what they considered to be Arnold-Chiari malforma tion by combined air and isotope ventricu伭 lography.

\section{METHODS}

Twenty nine infants suspected of having hydro cephalus were studied in the following way. Thro $\overrightarrow{0}$ drops of Lugol's solution were administered daily for $N$ nine days, starting on the day before the investigation, to block thyroid uptake of the isotope. After ventricular puncture through the fontanelle, cerebrospinal fluid was exchanged with a quantity of air, usually between 25 and $60 \mathrm{ml}$., depending on the degree of hydrocephalus. Subsequently a solution of $15 \mu \mathrm{c}$ of high specific activity radio-iodinated human serum albumin was injected through the ventricular needle, which was then withdrawn. During the subsequent radiological investigation the child was somersaulted into various positions in order to visualize the different parts of the ventricular system and subarachnoid spaces.

About four hours after the injection scintigraphs were made. Both the Anger type gamma camera $\delta$ and a rectilinear scanner were used, the camera giving a quick general orientation and the scanner 을 demonstrating finer details. A second and third $D$ investigation were made 24 and 48 hours after the injection, respectively. The infants were mildly $N$ sedated with diazepam before each investigation. O Care was taken to include the upper part of the $N$ cervical spine in the pictures, in order to demonstrate outflow of the radioactivity from the ventricular system into this region. 


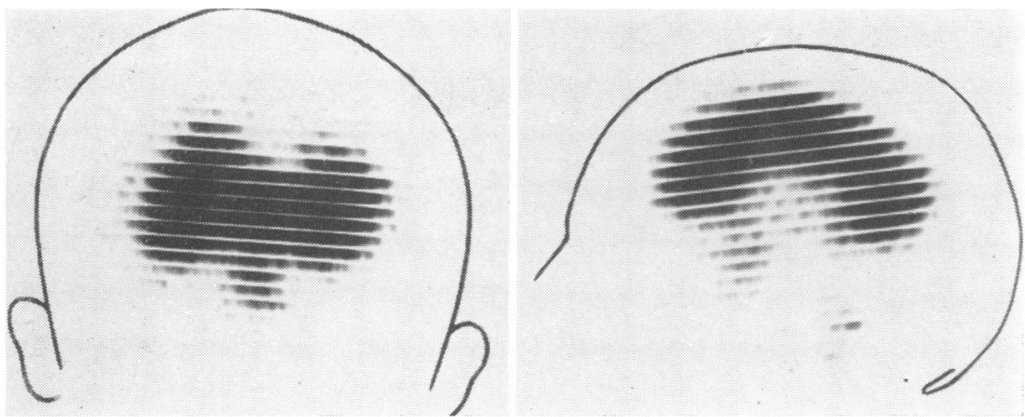

(a) Isotope ventriculography. Anterior and lateral view four hours after intraventricular injection of RIHSA. The enlarged lateral and third ventricles are demonstrated.
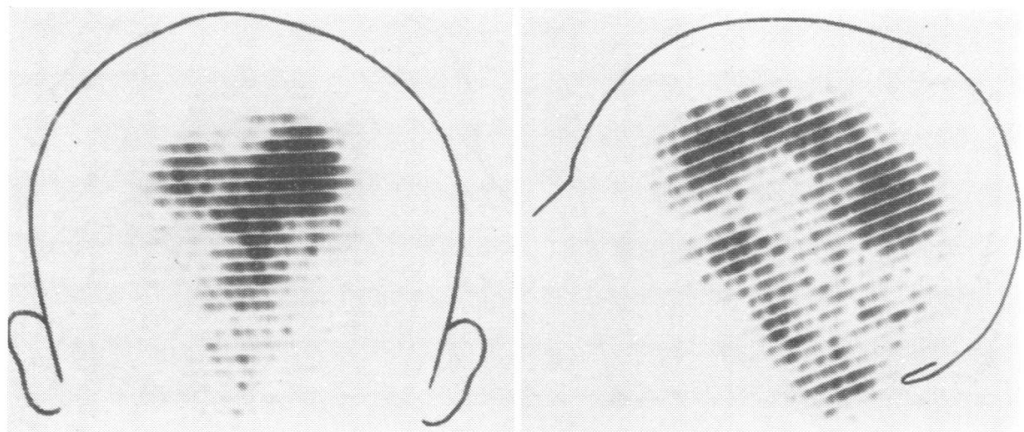

(b) Isotope ventriculography. Anterior and lateral view 24 hours after intraventricular injection of RIHSA. The tracer fills the subarachnoid space in the cerebellar and upper cervical region, and the basal cisterns. No activity is demonstrated in the subarachnoid space over the brain convexities.
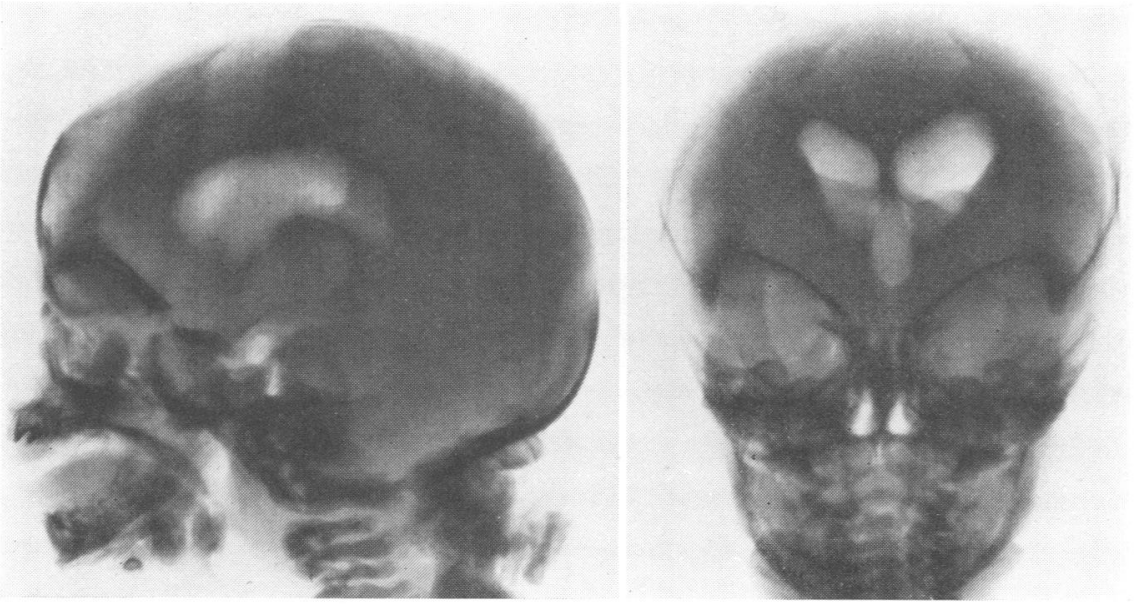

(c) Lateral air ventriculogram in brow-up position with horizontal beam. Enlarged lateral ventricles, temporal horns, and third ventricle are shown. Air is found on the anterior aspect of the brain-stem. No air in the sylvian fissures or over the brain convexities. (d) Anteroposterior projection. Enlarged lateral and third ventricles.

FIG. 1. Isotope and air ventriculography in a case of a communicating hydrocephalus: a week old baby with a lumbar meningomyelocoele and enlarged head. 

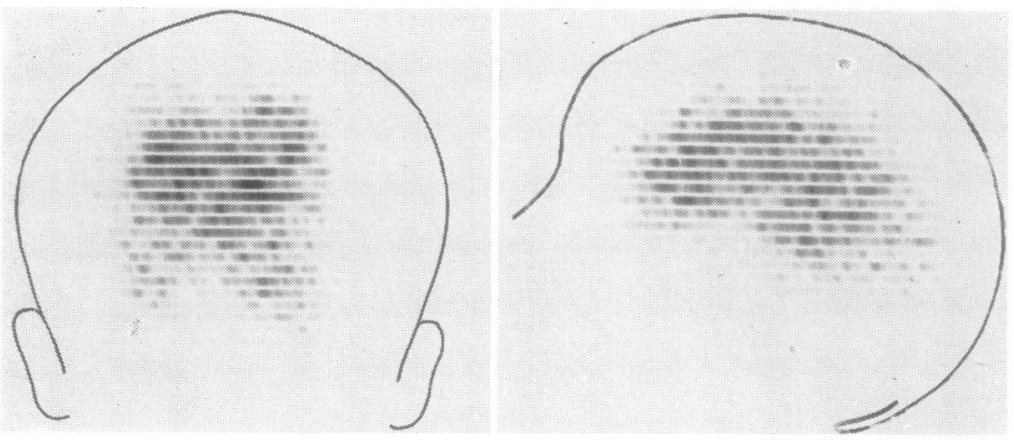

(a) Isotope ventriculography. Anterior and lateral view four hours after intraventricular injection of RIHSA. Enlarged lateral ventricles are demonstrated.
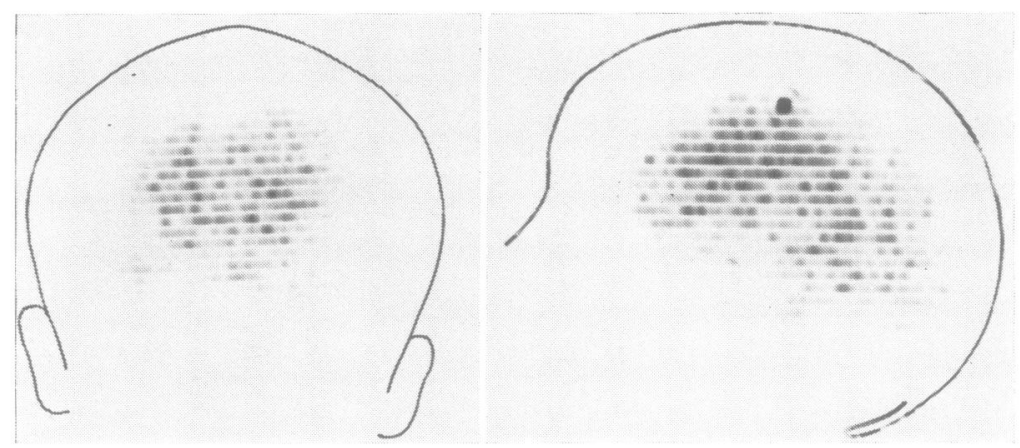

(b) Isotope ventriculography. Anterior and lateral view 24 hours after the injection. The isotope picture is essentially the same as the one after four hours. No activity is shown in the basal cisterns, sylvian fissures, cervical subarachnoid space, or over the brain convexities.
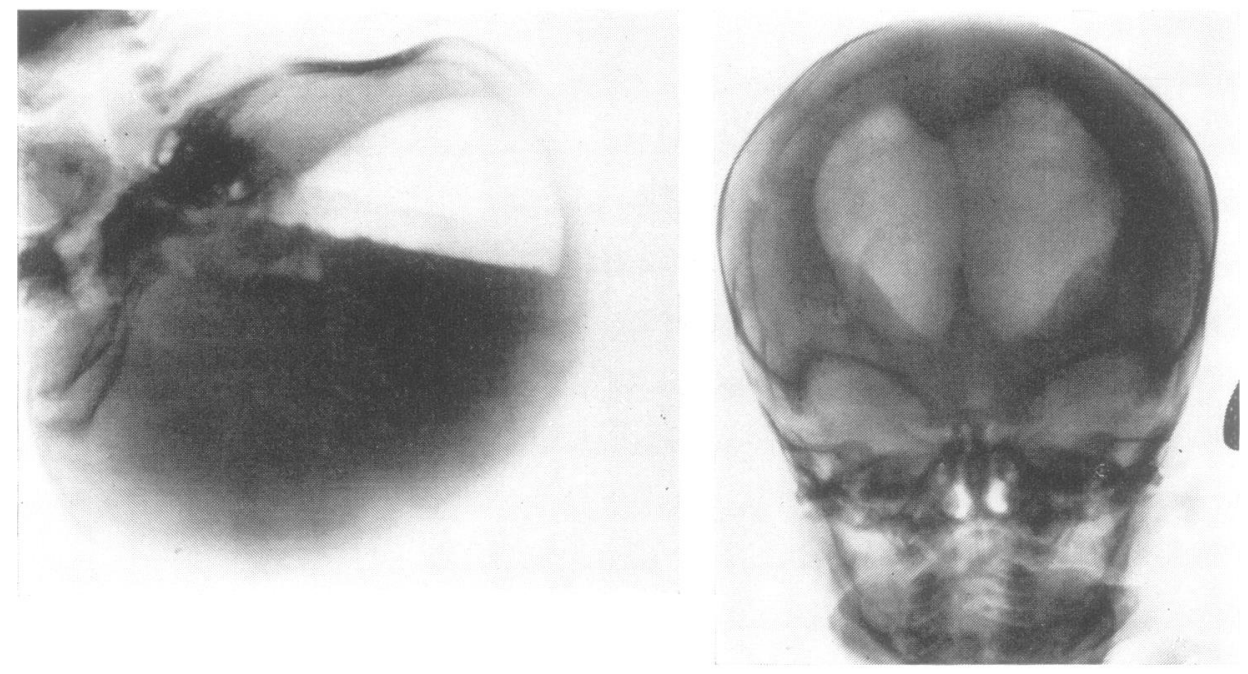

(c) Lateral air ventriculogram with horizontal beam. Patient in the brow-down position after somersaulting backwards. Enlarged lateral ventricles are shown. Some air is in the posterior part of the third ventricle but not in aqueduct or fourth ventricle. (d) Anteroposterior projection in brow-up position. The lateral ventricles are symmetrically enlarged. The third ventricle is faintly visible.

FIG. 2. Isotope and air ventriculography in a case of a non-communicating hydrocephalus: a 40 day old infant with a lumbar meningomyelocoele and enlarged head. 


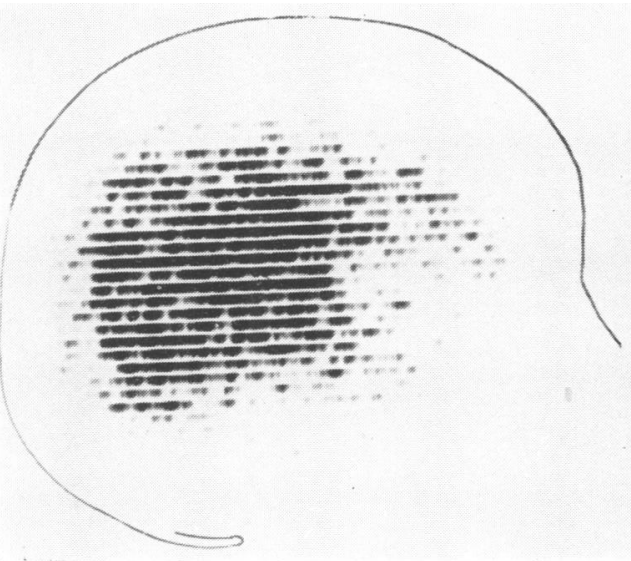

(a)

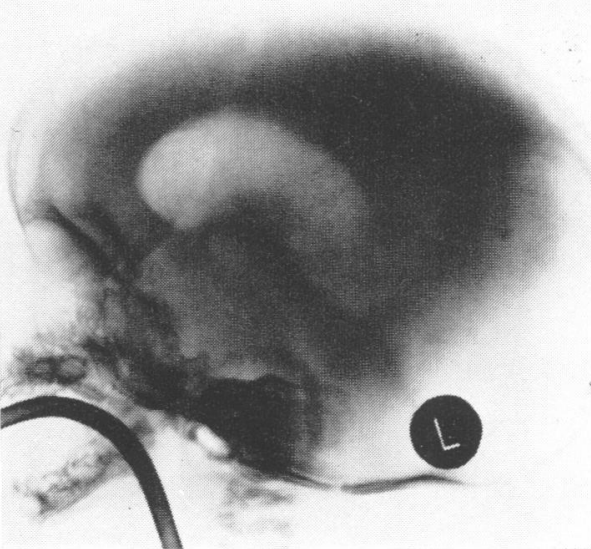

(b)

(a) Lateral isotope ventriculogram, made 24 hours after intraventricular injection, showing a big posterior porencephalic cyst. (b) Lateral air ventriculogram, with the patient lying on the left side and vertical $x$-ray beam of an enlarged right ventricle communicating with very big occipital porencephalic cyst.

FIG. 3. Isotope and air ventriculography in case of monoventricle and porencephalic cyst: a 42 day old baby with enlarged head.

Our first isotope ventriculograms were carried out with technetium albumin ( $\left.\mathrm{Tc}^{99 \mathrm{~m}} \mathrm{HSA}\right)$; its short half life, however, prohibited investigations after 24 and 48 hours, which was considered a major disadvantage.

\section{RESULTS}

The age of the 29 infants at the time of investigation was between 4 days and 6 months, most infants being less than 30 days old. The 16 children with meningomyelocoele (see Table) had a surgical correction of the defect before the investigation was performed. In two of the other babies there was evidence of trauma and subarachnoid haemorrhage during birth. Three babies had meningitis. Three babies had multiple congenital anomalies. Five babies did not fit into the conventional grouping of communicating or non-communicating hydrocephalus. One of them had one huge monoventricle (cyclopean ventricle) which could not be completely outlined by air. However, it was nicely depicted on the isotope-ventriculogram. Two babies had porencephalic cysts connected with the lateral ventricles. The cysts were demonstrated by isotope ventriculography. One baby suffered from severe meningitis after a brain abscess; the

\section{TABLE}

CAUSES AND SITES OF CEREBROSPINAL FLUID BLOCK IN 24 CASES OF HYDROCEPHALUS

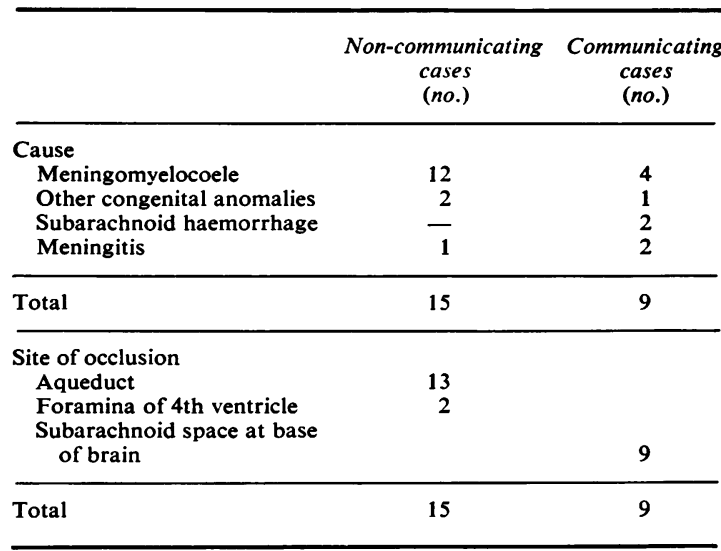

enlarged lateral ventricles were divided into several compartments, and, according to the isotope investigation, they were non-communicating. One baby had a tumour of the posterior fossa which was better demonstrated by air, whereas the isotope study showed only non-communicating hydrocephalus. 


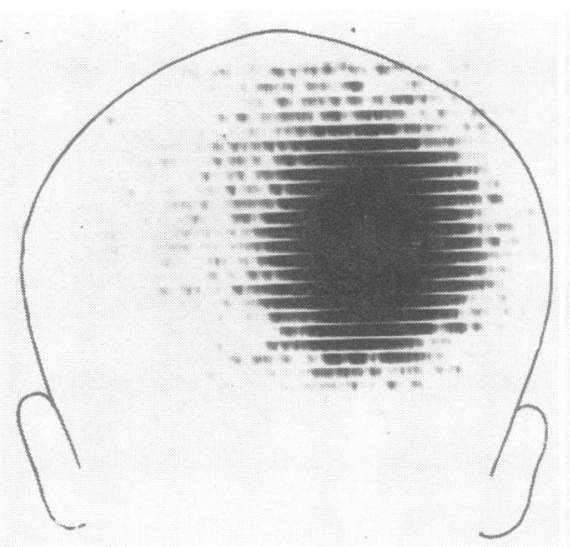

(a)

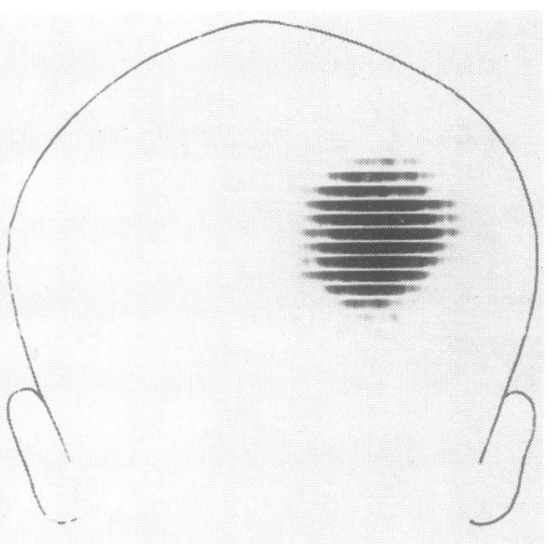

(b)

(a) Isotope ventriculography. Anterior view four hours after the intraventricular injection of RIHSA. The tracer fills only the left lateral ventricle into which it was injected. It does not pass to the other lateral ventricle or the third ventricle. (b) Isotope ventriculography. Anterior view 24 hours after the intraventricular injection. The tracer still does not pass beyond the left lateral ventricle.

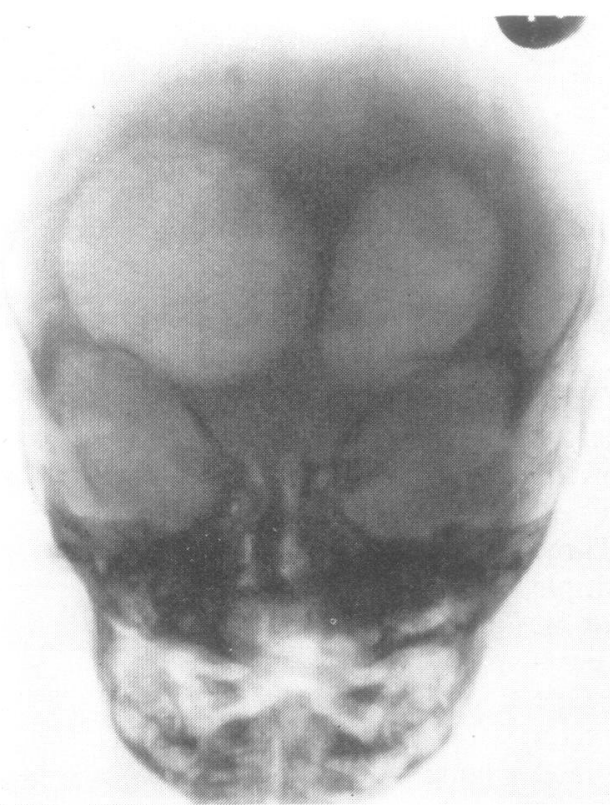

(c) Air ventriculogram.

Antero-posterior projection in supine position. Filling of both anterior horns effected by separate injections of both lateral ventricles. Slightly asymmetrical hydrocephalus with presence of small air bubbles in the right ventricle.

FIG. 4. Isotope and air ventriculography in a case of obstruction of both lateral ventricles: a 60 day old baby with enlarging head after severe meningitis. 
Figure 1 is the result of combined air and isotope ventriculography in a case of communicating hydrocephalus. In the isotope picture, made four hours after the injection, the tracer is demonstrated in the lateral, third, and fourth ventricles. Twenty-four hours after the injection the cervical subarachnoid space, basal cisterns, and sylvian fissures are visualized. There is no activity over the brain convexities, the flow of the isotope being obviously blocked at the outlet of the sylvian fissures. Air ventriculography of the same patient demonstrates moderately enlarged lateral ventricles and some air in the basal cisterns and cervical subarachnoid space.

A case of aqueduct stenosis is illustrated in Fig. 2. Isotope ventriculography does not show any passage of the tracer beyond the third ventricle. The 24-hour pictures are essentially the same as those made four hours after the intraventricular injection. The air study shows enlarged lateral ventricles, an enlarged third ventricle, and a complete stop of the air at the entrance to the aqueduct.

Figure 3 demonstrating the huge cyclopean ventricle, both by RIHSA and air, has to be elaborated somewhat like the previous figures. The case of meningitis and brain abscess is shown in Fig. 4.

\section{DISCUSSION}

Since the introduction of the study of cerebrospinal fluid dynamics in hydrocephalus, first by dyes and then by indirect isotopic methods, it has become evident that there is often a discrepancy between these investigations and air studies. Where air demonstrates a complete block of passage, the indirect isotope study may disclose only a partial obstruction or hindrance of flow. The reason for this discrepancy is that air, being an unphysiological agent, sometimes fails to pass regions that cerebrospinal fluid does. Therefore indirect studies with dyes and isotopes have been added to air studies in the evaluation of infantile hydrocephalus. However, these methods are complicated, sometimes unreliable, and the exact place of hindrance of flow is difficult to assess. Although positive contrast ventriculography sometimes may give useful information, the dangers and complications of this method are well known.

A simple and most informative solution is scintigraphy of the CSF spaces after intra- ventricular injection of RIHSA. The tracer marks the flow of cerebrospinal fluid, visualizing the ventricular system and subarachnoid spaces in subsequent examinations. RIHSA also penetrates cysts filled with cerebrospinal fluid and communicating with the ventricles or subarachnoid space. In air studies the investigator has to be aware beforehand of the possibility of the existence of such a cyst in order to manipulate the air into it, and even then this may fail. When the ventricles are markedly enlarged it is dangerous to use a large amount of air as this may cause collapse of brain tissue and haemorrhage. Isotope ventriculography is a very simple and harmless investigation. Even without a supplementary air study it gives a good general idea about the size and contour of the ventricles. It is the method of choice in severely sick children for whom air ventriculography is too dangerous and there is no reason to suspect a tumour.

A small quantity of RIHSA proves to be sufficient for good visualization of the CSF spaces. Brocklehurst (1968) used $50 \mu \mathrm{c}$, Castellino, Zatz, and DeNardo (1969) 50 to $75 \mu \mathrm{c}$. Although our investigations were started with injection of $50 \mu \mathrm{c}$, it proved to be possible to reduce the amount of radioactivity to $15 \mu \mathrm{c}$ without affecting the quality of the pictures. The very low amount of radioactivity administered and blocking of the thyroid with Lugol's iodine contribute to the safety of the technique.

It should be remembered that scintigraphic pictures have poor resolution compared with radiographs. Air gives a better visualization of anatomical structures and a better topographical localization. It has proved to be far superior in the detection of tumours and other space occupying lesions. The isotope investigation therefore should preferably be combined with air studies in order to have the best diagnostic results from two methods which supplement each other.

In the normal pattern of flow (Brocklehurst, 1968; Overbeek, 1968) the RIHSA injected into the lateral ventricles passes through the ventricular system to the subarachnoid space in the spinal canal and around the brain-stem. It is shown over the brain convexities in the 24-hour investigation. Hardly any activity is detected over the brain after 48 hours.

In non-communicating hydrocephalus the block or hindrance of flow may be anywhere in the ventricular system. It is, however, most common in the aqueduct and at the outlet of 
the fourth ventricle. Aqueduct obstruction is demonstrated scintigraphically by persistent filling of the lateral and third ventricle, without visualization of the fourth ventricle, cisterna magna, or spinal canal. In obstruction of the outlet of the fourth ventricle, the ventricle itself is filled with the tracer. Sometimes it may be markedly enlarged, as in the Dandy-Walker syndrome.

In communicating hydrocephalus the block is found in the subarachnoid pathways. The flow of the tracer is stopped in the basal cisterns or sylvian fissures but there is activity in the cisterna magna and cervical spinal canal. Communicating hydrocephalus may be difficult to diagnose with air ventriculography, especially if only a small amount of air escapes the ventricular system, insufficient to depict the cisterna magna, basal cisterns, or brain convexities. Isotope ventriculography gives a clearcut demonstration of cerebrospinal fluid block in the subarachnoid spaces.

In meningomyelocoele a non-communicating hydrocephalus was usually diagnosed (Table), with the stop localized in the aqueduct. However, in four cases the hydrocephalus proved to be of the communicating type, with the stop in the basal cisterns or sylvian fissures. The fact that air or isotope was never found over the convexities of the brain is interesting. It supports the theory of Gardner (1961) concerning undissection of the absorptive areas of the subarachnoid space during embryonic life as the cause of communicating hydrocephalus in myelomeningocoele. In all our other cases of communicating hydrocephalus an evident aetiology of haemorrhage or infection explained the non-filling of the convexities. Congenital origin of the block of the subarachnoid space over the brain convexities in these cases is very unlikely, as has been pointed out by Granholm and Rådberg (1963) and Lourie and Berne (1965).
We wish to thank Prof. Dr. J. W. F. Beks, head of the Neuro-surgical clinic and Dr. M. G. Woldring, head of the Central Isotope Laboratory of the $\mathbb{\infty}$ University Hospital of Groningen for their help and cooperation.

\section{REFERENCES}

Atkinson, J. R., and Foltz, E. L. (1962). Intraventricular 'RISA' as a diagnostic aid in pre- and postoperative $ᄋ$ hydrocephalus. Journal of Neurosurgery 19, 159-166.

Bannister, R., Gilford, E., and Kocen, R. (1967). Isotope encephalography in the diagnosis of dementia due to communicating hydrocephalus. Lancet, 2, 1014-1017.

Bell, R. L. (1957). Isotope transfer test for diagnosis of $\stackrel{\oplus}{\rightarrow}$ ventriculosubarachnoidal block. Journal of Neurosurgery, 14, 674-679.

Brocklehurst, G. (1968). Use of radio-iodinated serum al- $\bar{C}$ bumin in the study of cerebrospinal fluid flow. Journal of Neurology, Neurosurgery, and Psychiatry, 31, 162-168.

Castellino, R. A., Zatz, L. M., and DeNardo, G. L. (1969). ע Radioisotope ventriculography in the Arnold-Chiari ${ }^{\text {s }}$ malformation. Radiology, 93, 817-821.

Di Chiro, G. (1964). Movement of the cerebrospinal fluid in human beings. Nature, 204, 290-291.

Di Chiro, G., Reames, P. M., and Matthews, W. B. (1964). RISA-ventriculography and RISA-cisternography. Neuro$\log y, 14,185-191$.

Di Chiro, G. (1966). Observations on the circulation of the cerebrospinal fluid. Acta Radiologica (Diagnosis), 5, 988- ज 1002.

Gardner, W. J. (1961). Rupture of the neural tube. TEe cause of myelomeningocele. Archives of Neurology, 4, 1- 하

Granholm, L., and Rådberg, C. (1963). Congenital commugi-o cating hydrocephalus. Journal of Neurosurgery, $20, \triangle$ 338-343.

Laurence, K. M. (1959). Some applications of the urinaxy phenolsulphonphthalein excretion test in hydrocephaßiso and related conditions. Brain, 82, 551-565.

Lourie, H., and Berne, A. S. (1965). A contribution on the etiology and pathogenesis of congenital communicatif $\vec{\theta}$ hydrocephalus. Neurology (Minneap.), 15, 815-822.

McCullough, D. C., and Luessenhop, A. J. (1969). Evaluation of photoscanning of the diffusion of intrathecal RISA in infantile and childhood hydrocephalus. Journal of Neurosurgery, 30, 673-678.

McLaurin, R. L. (1969). Diagnostic study of suspected hydrocephalus. Journal of the American Medical Association, 208, 1359-1364.

Overbeek, W. J. (1968). Isotope investigation of hydrocephalus. Psychiatrica, Neurologica, Neurochirurgia, 71, 음 99-103.

Spoerri, O., and Rösler, H. (1965). Isotope ventriculography with $I^{131}$ and $I^{125}$ in the evaluation of hydrocephalus. Meeting of the Society for Research into Hydrocephalus and Spina Bifida, Groningen. 1965. Developmental and Child Neurology, Suppl. 11, 88-93. 